SHORT REPORT

\title{
Head injury and limb fracture in modern playgrounds
}

\author{
C Norton, K Rolfe, S Morris, R Evans, R James, M D Jones, C Cory, F Dunstan, J R Sibert
}

Arch Dis Child 2004;89:152-153. doi: 10.1136/adc.2003.024364

There were no serious head injuries in modern Cardiff municipal playgrounds with safety surfaces over five years injury surveillance. The literature suggests serious head injuries did occur before the introduction of safety surfaces.

$\mathrm{P}$ layground standards have been introduced throughout the Western world to promote safe play for children. They advise on the design, dimensions, and layout of playgrounds, including the use of impact absorbing surfaces. These surfaces were introduced primarily to reduce head injury; however, there has been controversy on their effectiveness. Ball has argued that they have not reduced injury, ${ }^{1}$ and raises doubts that their cost is justified. However, there is evidence that overall injuries are less frequent on safety surfaces. ${ }^{2}$ The majority of the literature has analysed playground injuries as a whole; however, it is head injury and fracture that really should concern us, as they are the injuries that might cause permanent disability and most morbidity to children. We are therefore presenting information on five years detailed surveillance of playground injury, focusing on head injuries and fractures. This has been achieved by the partnership between a University Department of Child Health, the Emergency Department, and the Council's Parks Service. $^{23}$

\section{METHODS AND RESULTS}

We studied any child $0-14$ years presenting to the Cardiff Royal Infirmary Emergency Department during 1994-98, whose location of injury was coded to a public playground in Cardiff. We correlated information on the injury and its location and mechanism with information on equipment and surface recorded by the Parks Service. We have described the injury surveillance scheme in detail in our previous work. ${ }^{2}{ }^{3}$ Concrete and tarmac surfaces in Cardiff playgrounds were phased out from 1994-95; this paper therefore focuses on head injuries and fractures to children on the modern playgrounds. These modern playgrounds all had bark or rubber impact absorbing surfaces with modern equipment and had maximum fall heights of less than 2.5 metres. We have confirmed fractures by clinical examination and interpretation of radiographs. We have compared these with similar injuries from all causes to Cardiff children in 1996-98 from the All Wales Injury Surveillance System.

We recorded a total of 473 children injured in Cardiff playgrounds with modern surfaces connected with equipment in the five years of the study (incidence 145 (95\% CI 131 to 159 ) per 100000 ) (table 1). Of these, 291 were from falls from equipment onto modern surfaces. A further 69 children were injured on tarmac or concrete playgrounds, mainly at the start of the study; they were not analysed in this paper. The mean age of children injured on the playgrounds was 6.96 years (range 11 months to 14 years); $57 \%$ of injuries were to boys. There were no deaths.

There were no children with skull fractures or needing more than overnight admissions for observation for head injury. Only two children were admitted overnight for observation because of head injury from falls onto modern surfaces: one bark and one rubber. They made a full recovery. The incidence of head injury needing overnight admission from playground falls to a modern surface is 0.6 (95\% CI 0 to 1.4) per 100000 . Serious head injury is therefore very rare on modern playgrounds.

In contrast there were $146 \mathrm{limb}$ fractures on playgrounds with modern surfaces (incidence 45 (95\% CI 38 to 52) per $100000)$. The majority were to the upper limb (137); this number represents $7 \%$ of all arm fractures to Cardiff children. Of these, the majority (128) were due to falls onto surfaces: mainly from climbing frames or monkey bars. Of the 146 children with fractures, a third (47) required hospital admission, mainly (42) for surgical intervention (mainly manipulation under anaesthesia). Table 2 shows details of the fractures.

\section{DISCUSSION}

Municipal playground injuries only represent a small proportion of the huge numbers of children attending the

Table 1 Injuries on modern playgrounds

\begin{tabular}{|c|c|c|c|c|}
\hline Type of injury & Total & Admissions & MUA & $\begin{array}{l}\text { Incidence per } 100000 / \text { year } \\
(95 \% \mathrm{Cl})\end{array}$ \\
\hline Playground injuries (1994-98) (equipment on modern surfaces) & 473 & & & 145 (131 to 159$)$ \\
\hline $\begin{array}{l}\text { Playground injuries (1994-98) (equipment on modern surfaces, falls } \\
\text { onto surface only) }\end{array}$ & 291 & & & 89 (79 to 99 ) \\
\hline $\begin{array}{l}\text { Playground head injury admission (1994-98) (equipment on modern } \\
\text { surfaces) }\end{array}$ & 2 (both falls) & & & $0.6(0$ to 1.4$)$ \\
\hline Playground fractures (1994-98) (equipment on modern surfaces) & 146 & 47 & 42 & 45 (38 to 52$)$ \\
\hline $\begin{array}{l}\text { Playground fractures (1994-98) (equipment on modern surfaces, falls } \\
\text { onto surface only) }\end{array}$ & 131 & 42 & 39 & 40 (33 to 47$)$ \\
\hline Playground arm fractures (1994-98) (equipment on modern surfaces) & 137 & 43 & 41 & $42(35$ to 49$)$ \\
\hline Playground arm fractures (1994-98) (equipment on modern surfaces, & 128 & 40 & 38 & 39 (32 to 46$)$ \\
\hline
\end{tabular}

MUA, manipulation under anaesthesia. 


\begin{tabular}{|lcll|}
\hline \multicolumn{2}{|l}{ Table 2} & Site and number of fractures & \\
\hline Site & Number & Breakdown & Number \\
\hline Hand & $4(3 \%)$ & & \\
Wrist & $75(51 \%)$ & Radius alone (2 bilateral) & 39 \\
& & Radius + ulna & 35 \\
& & Ulna & 1 \\
Forearm & $13(9 \%)$ & Radius + ulna & 11 \\
Elbow & $29(20 \%)$ & Humerus & 23 \\
& & Radius & 4 \\
& & Ulna & 2 \\
Upper arm & $3(2 \%)$ & Humerus & 3 \\
Shoulder & $13(9 \%)$ & Clavicle & 7 \\
& & Humerus & 6 \\
Nose & $3(2 \%)$ & & 3 \\
Lower limb & $6(4 \%)$ & Tibia & 2 \\
& & Tibia and fibula & 1 \\
& & Metatarsal & \\
\hline
\end{tabular}

accident department in a year. Head injury is now very rare in modern playgrounds. The question is whether this has reduced since the introduction of safety features such as safety surfacing.

The evidence pre-1985 when safety surfaces were initially introduced is sparse, so any quantitative study is difficult. When we systematically searched the literature we found three case series, which gave enough detail for qualitative analysis. The detailed descriptions ${ }^{4-6}$ in these papers that we have identified suggest that before the introduction of standards and safety surfaces there were serious head injuries. For instance, there was a sixfold greater chance of concussion and the severity of head injury was greater. ${ }^{4}$ This is what was intended by the introduction of safety surfacing. However, the proportion of injuries due to arm fractures is unchanged; they were a problem before and are a problem now in modernised playgrounds.

There are biomechanical reasons why safety surfaces may not protect against arm fracture. Experimental arm models suggest that the impact absorbing surfaces may be useful in attenuating forces from impacts involving falls from a standing height. However, in higher falls, such as falls from equipment in playgrounds, the surface is not successfully attenuating all of the force components, which result in fracture. $^{7}$

We believe we should now develop methods for overall playground safety, not only to prevent head injury but also to reduce arm fractures. Playgrounds offer wonderful developmental opportunities and are fun for children. Severe head injuries are now rare on modern playgrounds and the abandonment of safety surfacing may result in further significant head injuries. We now should wish to reduce fracture rates by developing surfaces that protect against head injury and fracture while ensuring that playgrounds remain places in which children want to play.

\section{ACKNOWLEDGEMENTS}

We thank particularly all the staff at the reception and children's area at the Emergency Department, for their help. We thank Professor Ronan Lyons and Ms Sarah Jones of AWISS for injury figures for all Cardiff children. Our work on playground injuries has been funded from the Wales Office of Research and Development (WORD), the Catherine Jenkins Memorial Trust, a playground equipment manufacturer (Hags), and the Charitable Funds of the previous Llandough NHS Trust. We thank Kenneth Kemp, Emeritus Professor and Honorary Senior Research Associate for his help at the beginning of our work.

\section{Authors' affiliations}

C Norton, K Rolfe, S Morris, F Dunstan, J R Sibert, R Evans, Accident and Emergency Department, Cardiff and Vale NHS Trust, UK

R James, Highways and Parks Service, Cardiff County Council, UK

M D Jones, C Cory, Medical Engineering Group, Cardiff University, UK

Correspondence to: Prof. J R Sibert, Department of Child Health, University of Wales College of Medicine, Llandough Hospital, Penarth CF64 2XX, UK; siberł@cardiff.ac.uk

Accepted 2 October 2003

\section{REFERENCES}

1 Ball D. Playgrounds: risks, benefits and choices. Contact research report. 426/2002. Health and Safety Executive, 2002.

2 Mott A, Rolfe K, James R, et al. Safety of surfaces and equipment for children in playgrounds. Lancet 1997;348:1874-6.

3 Sibert JR, Mott A, Rolfe K, et al. Preventing injuries in public playgrounds through partnership between health services and local authority: community intervention study. BMJ 1999;318:1595.

4 Illingworth C, Brennan P, Jay A, et al. 200 injuries caused by playground equipment. BMJ 1975:4:332-4.

5 Rivers RP, Boyd RD, Baderman H. Falls from equipment as a cause of playground injury. Community Health 1978;9:178-9.

6 Oliver TI, MacFarlane JP, Haigh JC, et al. Playground equipment and accidents. Aust Paediatr J 1981;17:100-3.

7 Robinovitch SN, Chiu J. Surface stiffness affects impact force during a fall on the outstretched hand. J Orthop Res 1998;16:309-13. 